\title{
Ferric Carboxymaltose Solution
}

National Cancer Institute

\section{Source}

National Cancer Institute. Ferric Carboxymaltose Solution. NCI Thesaurus. Code C91084.

A parenteral iron solution containing ferric iron complexed with carboxymaltose polymers, used in parenteral iron-replacement therapy. Upon administration, ferric carboxymaltose is removed from plasma by the reticuloendothelial system.

Subsequently, ferric iron binds to transferrin or is stored as ferritin. Transferrin-bound iron is transported in the plasma to the liver, spleen and bone marrow, where it is incorporated into hemoglobin, and to muscle, where it is incorporated into myoglobin. 